\title{
Technical note: A new comprehensive SCAVenging submodel for global atmospheric chemistry modelling
}

\author{
H. Tost, P. Jöckel, A. Kerkweg, R. Sander, and J. Lelieveld \\ Atmospheric Chemistry Department, Max-Planck Institute of Chemistry, P.O. Box 3060, 55020 Mainz, Germany \\ Received: 16 August 2005 - Published in Atmos. Chem. Phys. Discuss.: 2 November 2005 \\ Revised: 19 January 2006 - Accepted: 20 January 2006 - Published: 23 February 2006
}

\begin{abstract}
We present the new scavenging scheme SCAV, simulating the removal of trace gases and aerosol particles by clouds and precipitation in global atmospheric chemistry models. The scheme is quite flexible and can be used for various purposes, e.g. long term chemistry simulations as well as detailed cloud and precipitation chemistry calculations. The presence of clouds can substantially change the chemical composition of the atmosphere. We present a new method of mechanistically coupling gas phase, aerosol, cloud and precipitation chemistry, which enables studies of feedbacks between multiphase chemistry and transport processes.
\end{abstract}

\section{Introduction}

During the last decades the importance of scavenging and aqueous phase chemistry of trace gases and aerosols in global models has received much less attention than gas phase chemistry, at least partly due to computational limitations. The models generally included simplified scavenging parametrisations, implemented to achieve realistic global distributions of various species, for instance schemes with fixed scavenging efficiencies. With increasing computational power the process description has become more detailed, e.g. taking into account uptake into the aqueous phase according to Henry's law equilibrium (Lawrence and Crutzen, 1998; Crutzen and Lawrence, 2000). Aqueous phase chemistry has been calculated in a simplified way as well (e.g. the sulphur(IV) oxidation in cloud and rain droplets by ozone and $\mathrm{H}_{2} \mathrm{O}_{2}$; Roelofs and Lelieveld, 1995; Feichter et al., 1996). More detailed cloud chemistry has been calculated by Lelieveld and Crutzen (1991) and Liang and Jacob (1997), who came to different results with respect to the importance on the global scale. Especially since the indirect aerosol ef-

Correspondence to: $\mathrm{H}$. Tost

(tost@mpch-mainz.mpg.de) fects on climate through the cloud microphysics attract much attention in global modelling studies, the need to account for chemical cloud processing of trace gases and aerosols has grown.

Still, the applied schemes are sometimes very specific, i.e. designed for a limited number of applications, and there is a need for more flexible models that combine these applications so that interactions and feedbacks, e.g. between reactive sulphur and nitrogen compounds can be simulated.

Furthermore, chemical mechanisms for aqueous phase chemistry have been developed, e.g. MECCA (Sander et al., 2005) and CAPRAM (Ervens et al., 2003). Thus far these have been applied in box and cloud resolving models, and they provide a basis for further developments and application on the global scale.

Here we present the new multi-purpose and multi-phase scavenging scheme SCAV including both a simplified and a detailed algorithm (optional) and a comprehensive cloud and precipitation chemical mechanism. Trace gases as well as aerosol processes are taken into account. The internal complexity can be specified and adjusted to the scientific application. Since SCAV has been implemented following the MESSy (Modular Earth Submodel System) standard (Jöckel et al., 2005), application to 3D global general circulation models (GCMs) is straightforward.

\section{Model description}

The SCAV submodel is highly structured, and all calculations are performed in the smallest meaningful entity. For the physico-chemical process 'scavenging' this is a vertical column since the chemical composition of the rainwater that enters a grid box from above affects the scavenging in that particular layer as well as the layers below. The input for the SCAV submodel has to be provided by an external source, e.g. from a larger scale model or through prescribed

(C) 2006 Author(s). This work is licensed under a Creative Commons License. 
values. If available, liquid water content and an average droplet size can be used as input data, otherwise they can be estimated from precipitation rates or fluxes, e.g. following Mason (1971). Calculation of scavenging for each droplet or even for droplet size bins is not feasible within most models over a longer simulation period due to computational constraints. Therefore a monodisperse droplet spectrum is assumed for cloud droplets.

For liquid precipitation a rain droplet size distribution according to Best (1950) has to be assumed because of reasons to be described later (see Sect. 2.1).

In this work we refrain from the often used terms of "incloud" and "below-cloud" scavenging as they do not represent a physical process but only its location. Instead the terms nucleation scavenging (NS) and impaction scavenging (IS) are used, giving a more accurate process description. NS represents the dissolution of species during the nucleation and growth of cloud droplets by microphysical processes that can result in precipitation formation. The term IS is used for falling rain droplets that impact with gas molecules and aerosols resulting in their uptake. This is more suitable because precipitation, formed at a higher altitude, falling into a cloud layer leads to IS even though this may happen within a cloud. Both processes have to be strictly distinguished because the droplet diameter can differ by orders of magnitude.

Within the column, the scavenging process starts in the uppermost layer where a cloud occurs (NS). In the layer below, the IS by the incoming precipitation flux is calculated first, followed by NS in that particular layer. If there are no clouds in this layer, the NS is neglected and only IS is calculated.

SCAV also calculates the aqueous phase chemistry in cloud droplets. Many reactions (e.g. the oxidation of $\mathrm{SO}_{2}$ ) proceed at rates very different from those in the gas phase. The aqueous phase chemistry is calculated for both precipitating and non-precipitating clouds, accounting for the chemical cloud processing of aerosols and air for the latter after cloud evaporation.

\section{Technical realisation:}

The technical realisation for the scheme is sketched in Fig. 1. The coloured boxes describe the new approach compared to the fixed coefficients commonly used in former models. The sketch also shows that input values (liquid water content (LWC), rain rate, etc.) for the clouds and precipitation are required. The coding standard defined by the MESSy structure (Jöckel et al., 2005) is strictly followed. The submodel interface layer (SMIL) organises the necessary data flow from the base model, which can be either a column model or a GCM, into the calculation of the scavenging process in the submodel core layer (SMCL).

The required input parameters are: temperature $(\mathrm{K})$, pressure $(\mathrm{Pa})$, cloud liquid water content $(\mathrm{kg} / \mathrm{kg})$, precipitation formation $(\mathrm{kg} / \mathrm{kg})$, cloud ice content $(\mathrm{kg} / \mathrm{kg})$, snow formation $(\mathrm{kg} / \mathrm{kg})$, rain and snow flux $\left(\mathrm{kg} /\left(\mathrm{m}^{2} \mathrm{~s}\right)\right)$, cloud cover, tracer mixing ratios ( $\mathrm{mol} / \mathrm{mol})$, aerosol radius $(\mathrm{m})$ and mode width (for modal aerosol modules), photolysis rates for individual species $(1 / \mathrm{s})$, and some quantities describing the grid box (mass, volume, horizontal size). The submodel has its own species structure, as defined and used in the SMCL. The "translation" into this structure can be done in the SMIL and is largely automated by preprocessing scripts.

User interaction controls the internal complexity of the submodel by setting switches in the namelist, namely:

- IS and/or NS

- gas phase and/or aerosol species scavenging

- scavenging by liquid water and/or ice

Additionally, the complexity of the scheme is either selectable by the choice of the aqueous phase chemistry mechanism (described later) or the scavenging parametrisations.

The output are tendencies for the tracer mixing ratios, the wet deposition fluxes for the considered species, and $\mathrm{pH}-$ values in clouds and precipitation.

\subsection{Gas scavenging and liquid phase chemistry}

The scavenging of gases can be calculated following two different approaches: First, in the classical approach with empirically determined, fixed scavenging coefficients (estimated from previous studies and Henrys law coefficients), and second by a system of coupled ordinary differential equations (ODE), explicitly describing the processes involved. The first has the advantage of being computationally efficient, e.g. in long-term climate simulations, whereas the second resolves feedback mechanisms between the multi-phase chemistry and transport processes involved. For the second approach the Kinetic PreProcessor (KPP) is applied including an adequate numerical equation solver (Damian et al., 2002; Sandu and Sander, 2005).

The processes of uptake and release of gases from the cloud or rain droplets is formulated following the Henry's law equilibrium and a correction for gas phase diffusion limitation and the accommodation coefficients.

Additional processes taking place in the liquid phase are:

- Transfer reactions (described in detail below)

- Dissociation of acidic and alkaline species (acid-base equilibria)

- Redox reactions in the liquid (e.g. sulphur(IV) oxidation by $\mathrm{H}_{2} \mathrm{O}_{2}$ and $\mathrm{O}_{3}$ )

- Photolysis reactions in the liquid phase (e.g. of $\mathrm{H}_{2} \mathrm{O}_{2}$ )

- Heterogeneous reactions on the surface of the droplets (e.g. gaseous $\mathrm{N}_{2} \mathrm{O}_{5}$ reacts on an aqueous surface with $\mathrm{H}_{2} \mathrm{O}$ to $\mathrm{HNO}_{3}$ ). 


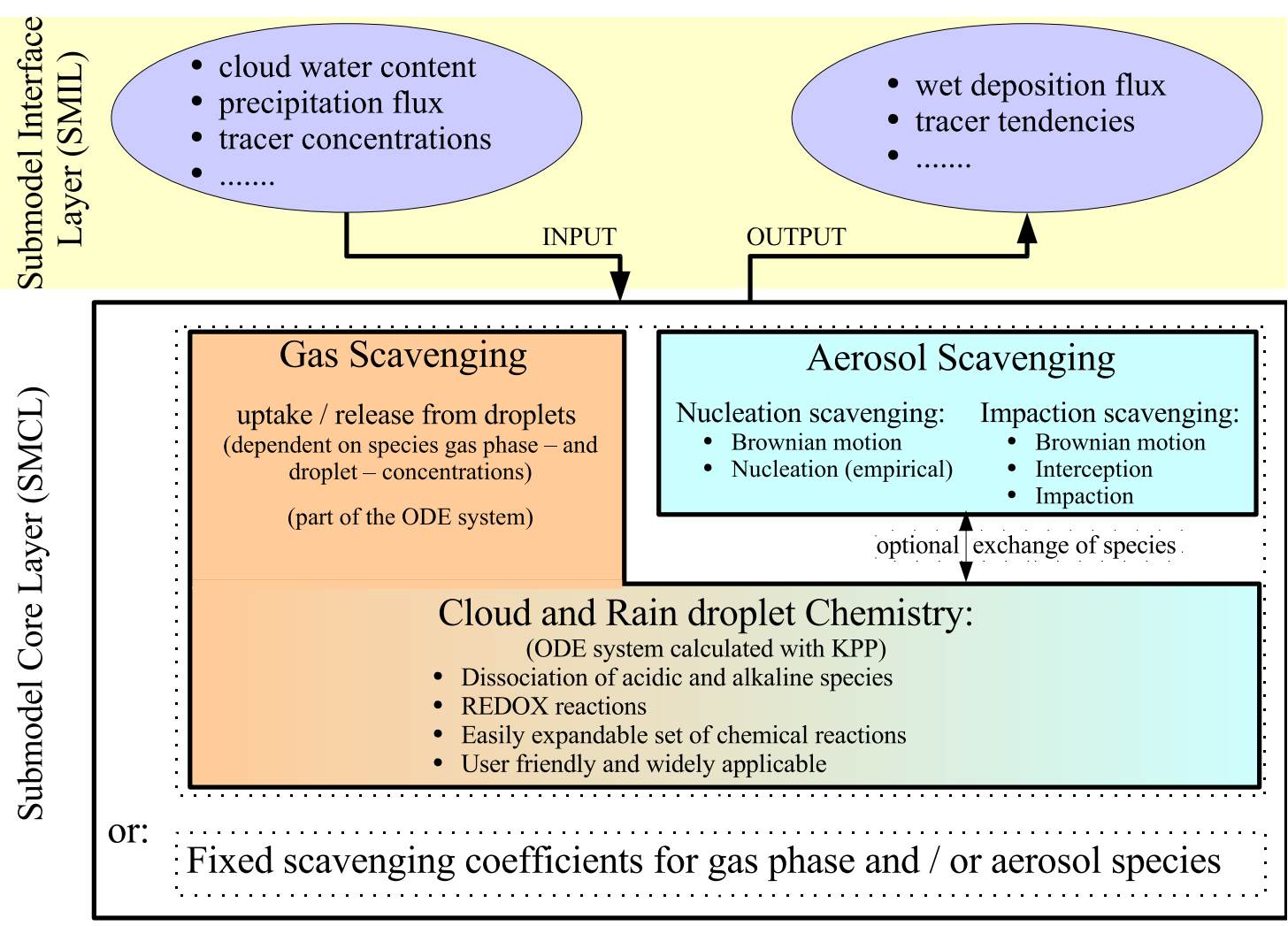

Fig. 1. Schematic representation of the scavenging and multiphase chemistry scheme. For the complete list of input and output parameters, see the model description section.

These processes are described by a coupled system of ODEs. Using KPP, the chemical reaction system can easily be altered without changes in the code (only automated scripts need to be run) and therefore it is applicable to a wide range of tasks of various complexity. The available liquid phase reaction set is identical to that of Sander et al. (2005), with some additions from Ervens et al. (2003). The reaction rates are calculated at each model time step and in each model level, depending on the meteorological input data (i.e., temperature, pressure, liquid water content (LWC)). A full range of choices is possible, but very detailed liquid phase chemistry becomes computational intensive.

An adequate minimum scavenging mechanism for current tropospheric chemistry systems contains the transfer of about 35 species into and out of the droplets, their dissociation equilibria and the liquid phase oxidation of $\mathrm{SO}_{2}$ to $\mathrm{SO}_{4}^{2-}$ by $\mathrm{O}_{3}$ and $\mathrm{H}_{2} \mathrm{O}_{2}$ (45 reactions). This is still computationally efficient while simulating the major known influences on tropospheric photochemistry. For further improvements and tests it is possible to calculate a comprehensive aqueous phase chemistry considering more than 70 inorganic and organic species with up to 130 reactions, or selecting even more chemical reactions, e.g. including transition metal chemistry.
Detailed results of such a study on a global scale will be presented in an upcoming paper (Tost et al., 2006 ${ }^{1}$ ).

\section{Technical realisation:}

A liquid chemistry mechanism has to be selected before starting a simulation. This is done by an automated script similar to that described by Sander et al. (2005). This script applies the KPP software and automatically creates Fortran90 code for the calculation and solution of the chemical mechanism. Additionally it builds the chemical species structure of the SMCL and creates the routines that manage the transfer from a different species structure into that of the submodel (part of the SMIL). The new liquid phase chemistry calculation code is part of the SMCL, too. After compilation the simulation takes into account scavenging as well as the cloud and precipitation chemistry of all selected reactions.

Because the model time step of global models is relatively long for chemistry integrations a model time step has to be subdivided into several sub-time-steps. Tests have shown that a Rosenbrock solver with automatic time step control

\footnotetext{
${ }^{1}$ Tost, H., et al., in preparation, 2006.
} 
is best suited for this specific task, since it can be applied to very stiff ODE systems (see also Sandu et al., 1997).

During each time step the entire tropospheric column of the model domain needs to be taken into account. This is essential because the uptake of species from the gas phase is also limited by the amount that is already dissolved in the precipitation. For each layer the chemical composition of the precipitation falling from the layers above determines the starting concentrations in the liquid phase while the gas phase concentrations are determined by the ambient values of the actual layer. The wet deposition flux out of the lowest model layer represents the chemical composition of rain water. Since usually only a small fraction of a grid box is affected by clouds and precipitation, only the cloud covered part or the part in which the precipitation occurs contributes to the scavenging, while the rest of the grid box remains unchanged. The cloud cover is one of the required input values. This bulk approach does not take into account the cloud structure in the grid box, since this information is often not provided by models, not even for cloud microphysics.

For very simple test cases also fixed scavenging coefficients are implemented in the scheme and can be selected in the namelist controlling the SCAV submodel. However, this approach is not recommended for regular atmospheric chemistry applications.

Within the chemical mechanism the reaction rates also include the transfer coefficients. These are limited by gas phase diffusion, which can be calculated from the atmospheric conditions and the molecular weight of individual species following:

$D_{g}=\frac{\bar{v} \cdot \lambda}{3}$

Here $\bar{v}$ represents the mean molecular velocity from the Boltzmann velocity distribution (in $\mathrm{m} / \mathrm{s}$ ) and $\lambda$ the mean free path (in $\mathrm{m}$ ) at the particular atmospheric conditions resulting in the diffusivity $\mathrm{D}_{g}$ of the respective gas in the air in $\mathrm{m}^{2} / \mathrm{s}$.

For cloud droplets the transfer coefficient can be described by the following equation (Schwartz, 1986):

$k_{m t}=\bar{v} /\left(r \cdot\left(\frac{r}{\lambda}+\frac{4}{3 \alpha}\right)\right)$

In this equation the transfer coefficient $k_{m t}$ has the unit $\mathrm{s}^{-1}$, $r$, the droplet radius is given in $\mathrm{m}$ and $\alpha$, the accommodation coefficient, is dimensionless. Even though the assumption of an average cloud droplet radius does not reflect the reality, the error made by this approach is sufficiently small, since the transfer velocity of gaseous species does not differ much in the size range of cloud droplets.

For falling rain droplets the equation originally derived by Frössling (1938) is used:

$v_{t}=\frac{D_{g}}{2 r} \cdot\left(2+0.6 \sqrt{\frac{2 \cdot r \cdot u}{v}}\left(\frac{v}{D_{g}}\right)^{1 / 3}\right)$

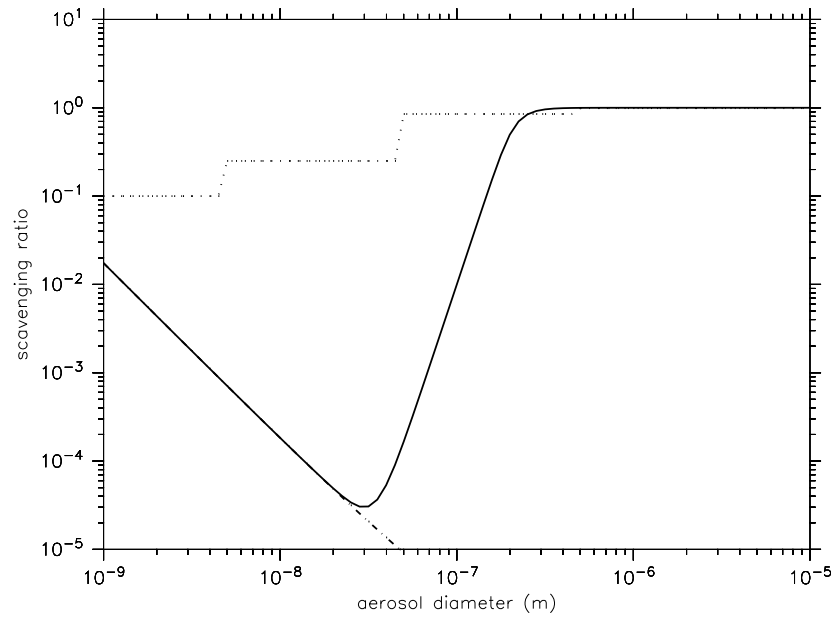

Fig. 2. Nucleation scavenging based on an empiric curve as a function of aerosol diameter (solid line: total scavenging efficiency (following Eq. (9)); dashed line: effect of Brownian motion in a cloud with a LWC of $1 \mathrm{~g} / \mathrm{kg}$; dotted line: parametrisation by Stier et al., 2005).

Here $v_{t}$ is the transfer velocity across the droplet surface in $\mathrm{m} / \mathrm{s}, u$ (the terminal velocity of the falling droplets) is given in $\mathrm{m} / \mathrm{s}$ and $v$ is the kinematic viscosity of air in $\mathrm{m}^{2} / \mathrm{s}$. Since the precipitation is not monodisperse, a droplet size distribution has to be assumed because an average droplet size would underestimate the effective transfer coefficient. Therefore an integrated transfer velocity over all droplet sizes weighted with the distribution function of Best (1950) is calculated. To obtain the same transfer coefficient as in Eq. (2) a geometry factor has to be applied to transform the velocity across the surface into a reaction rate coefficient:

$k_{m t}=\frac{3 v_{t}}{r}$

For the determination of the transfer reaction rate coefficients ( $k_{\text {exf:f }}$ (forward) and $k_{\text {exf:b }}$ (backward), both in $\mathrm{s}^{-1}$ ), $k_{m t}$ has to be multiplied with the LWC (in $\mathrm{m}_{\mathrm{water}}^{3} / \mathrm{m}_{\text {air }}^{3}$ ) for the forward and with the dimensionless Henry coefficient $H_{x}$ for the backward reaction rate (Sander, 1999).

$k_{\text {exf:f }}=k_{m t} \cdot L W C$
$k_{\text {exf:b }}=k_{m t} \cdot H_{x}$

The dissociation reactions follow the Arrhenius formula, and the oxidation reaction rates are taken from the literature (see the supplement of Sander et al., 2005).

\subsection{Aerosol scavenging}

For this process SCAV also contains the dual approach using fixed coefficients as well as online calculated scavenging coefficients. The latter calculation, being recommended for atmospheric chemistry applications is dependent on aerosol 


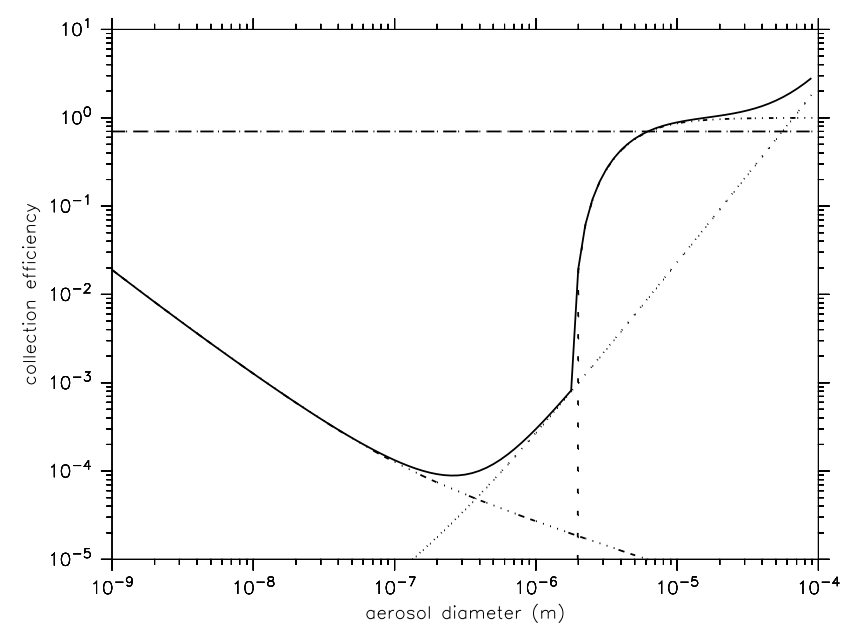

Fig. 3. Impaction scavenging and the effect of contributing processes on the collection efficiency as a function of aerosol diameter (solid line: total collision efficiency (according to Eq. (10)); dash-dotted line: Brownian motion; dotted line: interception; short dashed line: impaction; medium dashed line: constant efficiency (for comparison only)).

and droplet radius. Different parametrisations are implemented for nucleation and impaction scavenging: the nucleation scavenging takes into account Brownian motion (following Seinfeld and Pandis, 1997) while the nucleation and growth to cloud droplets is parameterised with an empiric function shown in Fig. 2. The aerosol nucleation scavenging ratio is plotted versus the aerosol radius. For the small particles the Brownian motion (dashed line) is dominant. For the larger particles, above a threshold of about $0.1 \mu \mathrm{m}$, the nucleation and growth of cloud droplets is dominant, rapidly reaching $100 \%$ aerosol scavenging ratio. The function for the larger aerosol particles has been empirically determined by measurements within clouds. Both processes in combination result in a ratio shown by the solid line. The dotted line shows a recently used parametrisation for NS in water clouds by Stier et al. (2005). For the small particles of the nucleation and Aitken mode the latter parametrisation yields much higher values.

Impaction scavenging depends on Brownian motion, interception, and impaction following a formula originally described by Slinn (1983). Its applicability has also been shown by Andronache (2003, 2004). Figure 3 shows the three major processes that control impaction scavenging, showing the collection efficiency as a function of the aerosol radius for rain droplets with $1 \mathrm{~mm}$ radius. The dotted dashes show the Brownian motion induced scavenging, again dominant for the smallest particles. The dotted line depicts the interception and the short dashes the results of impaction. Impaction and interception are clearly dominant for the larger particles. The solid line shows the net effect. For comparison, a constant collection efficiency of 0.7 for all aerosol sizes, which

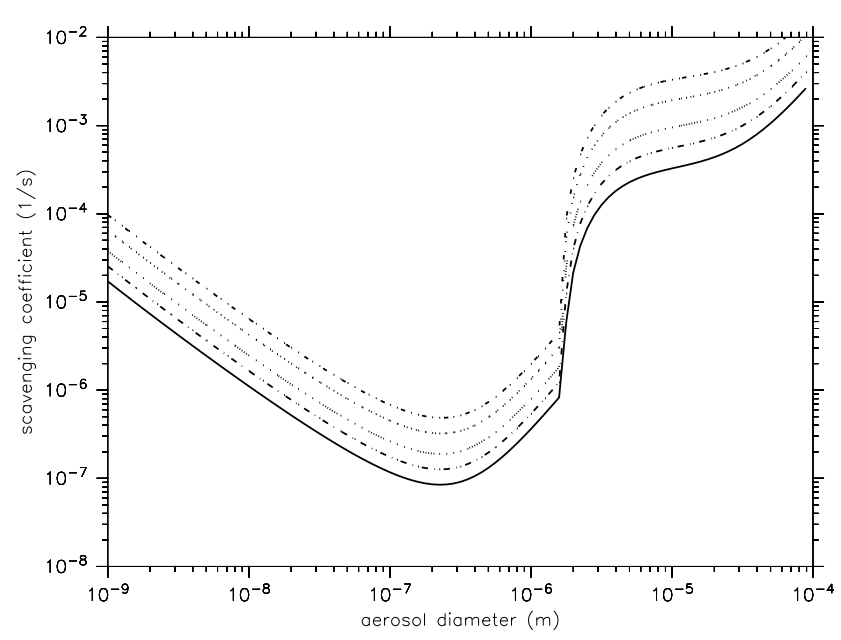

Fig. 4. Impaction scavenging coefficient for various rain rates (from bottom to the top: $0.5 \mathrm{~mm} / \mathrm{h}, 1 \mathrm{~mm} / \mathrm{h}, 2 \mathrm{~mm} / \mathrm{h}, 5 \mathrm{~mm} / \mathrm{h}, 10 \mathrm{~mm} / \mathrm{h}$ ) as a function of aerosol diameter (calculated with Eqs. (10) and (12)).

is a commonly used parameter in simple parametrisations, is plotted (medium dashes). It is obvious that this does not represent the physical processes involved.

Both figures show the well known 'scavenging gap', being slightly shifted to the smaller particles for nucleation scavenging compared to impaction scavenging.

Since there is a dependency on rainfall intensity and droplet size, Fig. 4 shows the scavenging coefficient for five rain rates $(0.5 \mathrm{~mm} / \mathrm{h}, 1 \mathrm{~mm} / \mathrm{h}, 2 \mathrm{~mm} / \mathrm{h}, 5 \mathrm{~mm} / \mathrm{h}, 10 \mathrm{~mm} / \mathrm{h}$ from lower to the upper curve, respectively). Following Mason (1971), the mean rain droplet radius depends on the rain rate, yielding radii of $0.32 \mathrm{~mm}, 0.37 \mathrm{~mm}, 0.42 \mathrm{~mm}, 0.51 \mathrm{~mm}$ and $0.59 \mathrm{~mm}$, respectively.

The scavenging of aerosols by frozen hydrometeors is parameterised following Stier et al. (2005). This is determined by a constant scavenging coefficient for each mode of the modal aerosol distribution.

\section{Technical realisation:}

The parametrisations described above are part of the SMCL. The calculated aerosol concentrations in the base model are transferred in the SMIL into local fields of the SMCL, similarly to the gas phase species. In each grid box NS and IS are calculated in the same way as described for the gas phase scavenging adopting the required input values in subroutines of the SMIL. Again the scavenged fraction is stored in the wet deposition flux separately for each aerosol species.

Within the SMCL for nucleation scavenging the Brownian motion effect is determined by the semi-empirical formula from Pruppacher and Klett (2000):

$$
\Lambda_{B}=\frac{1.35 \cdot L W C \cdot D_{p}}{r_{\text {rain }}^{2}}
$$


Here $\Lambda_{B}$ represents the scavenging coefficient for Brownian motion in $\mathrm{s}^{-1}$, the LWC is in $\mathrm{g} / \mathrm{cm}^{3}, D_{p}$ is the diffusivity of the particle in $\mathrm{m}^{2} / \mathrm{s}$ and the unit of the cloud droplet radius $r_{\text {rain }}$ is $\mathrm{m}$. This coefficient is applied in an exponential approach for each aerosol species:

$C\left(t_{0}+\Delta t\right)=C\left(t_{0}\right) \cdot \exp \left(-\Lambda_{B} \cdot \Delta t\right)$

$C$ is the concentration of a species and $\Delta t$ the model time step in $\mathrm{s}$. The empirical function for the nucleation of cloud droplets is applied in a different way. In this case it is not the scavenging coefficient, but the scavenging ratio, calculated by:

$C=C_{0} \cdot\left(1-\arctan \left(\left(5.0 \cdot 10^{6} \cdot r_{\mathrm{aer}}\right)^{6}\right) \cdot 2 / \pi\right)$

For this parametrisation the aerosol radius $r_{\text {aer }}$ is used in $\mathrm{m}$. The scavenging ratio resulting from this equation is shown in Fig. 2. The equation is derived from the measurements presented by Svenningsson et al. (1997) and Martinsson et al. (1999). While Eq. (9) describes only the uptake of aerosol particles in cloud droplets, the actual removal of aerosol particles by the cloud depends on the ratio of precipitation production to the liquid water content of the cloud. Since the uptake is formulated without using cloud droplet attributes, an assumption about the cloud droplet distribution is not required.

It is assumed that the microphysical properties of the cloud and precipitation formation are already calculated by other submodels and can be used as input values. If the aerosol distribution is already used for this purpose and modified by this process, the aerosol nucleation scavenging of the presented submodel should not be applied. A formulation of aerosolcloud interactions considering the supersaturation and chemical composition of the aerosol would be useful, but has not been implemented in the model system yet. Due to this lack, the simplified approach has been made.

For impaction scavenging the scavenging coefficient is calculated from the collision efficiency shown in Fig. 3. This dimensionless efficiency $E$ is determined by:

$$
\begin{aligned}
& E=\frac{4}{\operatorname{ReSc}}\left(1+0.4 R e^{1 / 2} S c^{1 / 3}+0.16 R e^{1 / 2} S c^{1 / 2}\right)+ \\
& 4 \Phi\left(\omega^{-1}+\left(1+2 R e^{1 / 2}\right) \Phi\right)+ \\
& \left(\frac{S t-S^{*}}{S t-S^{*}+2 / 3}\right)^{3 / 2}
\end{aligned}
$$

$R e$ is the Reynolds number of the rain droplet, $S c$ the Schmidt number of the collected aerosol particle, St the Stokes number of the collected particle, $\Phi$ the ratio of radii of particle and droplet $\left(r_{\text {particle }} / r_{\text {droplet }}\right)$, and $\omega$ the viscosity ratio of water to air. The parameter $S^{*}$ is derived from the Reynolds number by:

$S^{*}=\frac{1.2+\frac{1}{12} \ln (1+R e)}{1+\ln (1+R e)}$
For this calculation the terminal velocity of the raindrops is computed following Beard and Pruppacher (1969). Parametrisations and definitions of all other required parameters can be found in the textbooks of Pruppacher and Klett (2000) and Seinfeld and Pandis (1997). Subsequently, the scavenging coefficient can be calculated by:

$\Lambda=\frac{E}{r_{\text {rain }}} \cdot 0.75 \cdot F_{\text {rain }}$

Here again $\Lambda$ is the scavenging coefficient in $\mathrm{s}^{-1}, r_{\text {rain }}$, the radius of the droplet, is given in $\mathrm{mm}$, the effective precipitation flux $F_{\text {rain }}$ in $\mathrm{kg} \mathrm{m}^{-2} \mathrm{~s}^{-1}$, pertaining to the fractional dimensionless part of the grid box covered by precipitating clouds. The coefficient $\Lambda$ is applied as in Eq. (8).

\subsection{Coupling of aerosol scavenging and liquid phase chem-} istry

When the chemical composition of the aerosol has been calculated, a coupling between the aerosol and gas phase scavenging is required because of the chemical interaction in the aqueous phase. Note that it is irrelevant whether a specific molecule originates from a dissolved aerosol particle or from gas phase species (e.g. sulfate, which can be transferred by sulfate aerosol particles, by the dissolution of gaseous $\mathrm{H}_{2} \mathrm{SO}_{4}$ or by the liquid phase oxidation of $\mathrm{SO}_{2}$ ). Furthermore, the chemical cloud processing of aerosol particles which have not been removed from the atmosphere by wet deposition, but rather have been released through droplet evaporation can thus be addressed explicitly.

\section{Technical realisation:}

The calculations in each column are performed stepwise. First, as described above, NS is calculated for aerosol species, afterwards the chemically active, scavenged fractions are used as initial concentrations for the species in the liquid. Effectively, there is only a different transfer mechanism for these species (dissolution of aerosol particles compared to diffusive uptake from the gas phase). Next, the gas phase concentrations from the base model are fed into the chemical core and assigned to the selected chemical species. Now the actual chemical integration is performed including the reactions and transfer mechanisms from and into the gas phase. If species of limited solubility enter a model layer with low gas phase concentration these can partly be transferred to the gas phase. Additionally, the aqueous phase chemistry in the droplets may cause a release of species produced within the droplets, e.g. chloride ions that have been reduced in chemical reactions can be released as volatile chlorine species to the gas phase. At the end of each time step it is assumed that the cloud completely evaporates and all volatile species will be released to the gas phase, while the ions are transferred to the aerosol phase, thus affecting the aerosol properties. As an example, the $\mathrm{SO}_{2}$ oxidation to 
$\mathrm{SO}_{4}^{2-}$ can significantly increase the aerosol sulfate amount. The evaporation approach is used for numerical reasons, because the model would become computationally very expensive if in addition to the gas phase species all aqueous phase species including ions were to be transported together with the cloud water. Since usually longer time steps are used for transport compared to the chemistry sub-steps, the difference in the uptake time is expected to be of less importance. The ratio of the precipitation formation to the total cloud water content within one time step determines the fraction of the species actually scavenged, entering the next lower grid-box by the precipitation flux.

For the impaction scavenging the procedure is similar. First the aerosol impaction scavenging is calculated. Subsequently, for chemically active species (determined by the selected mechanism) the transformation of scavenged aerosol material into the rain water is performed and subtracted from the aerosol wet deposition flux. Then the chemical integration is performed and the species concentrations are stored in the wet deposition flux for the layer below.

Several degrees of coupling complexity can be selected by the user, depending how detailed the information of the chemical composition of the aerosol can be provided. If there is no aerosol submodel available, assumptions are made to create a set of passive aerosol tracers (e.g. aerosol sulphate, nitrate, $\mathrm{H}^{+}$, and ammonium) to ensure mass conservation. These are affected by the typical aerosol sinks, but microphysical aerosol properties are not assigned.

\subsection{Evaporation of rain and release of dissolved species}

If cloud or falling rain droplets evaporate completely the dissolved species are released. Any neutral, volatile compound is transferred to the gas phase. Scavenged aerosol particles are redistributed into the aerosol distribution. In many previous model approaches, the ions were neglected, assuming that they would stay attached to aerosols and eventually be scavenged by precipitation before they would be released back to the gas phase. Alternatively they were transferred back into the gas phase species from which they originate (e.g., $\mathrm{NO}_{3}^{-}$is released as gaseous $\mathrm{HNO}_{3}$ ). The former approach is not mass conserving and neither assumption is physically and chemically realistic. Due to the coupling with the aerosols this weakness has been overcome in the new scheme.

\section{Technical realisation:}

Note that we do not apply the commonly used approach to release part of the dissolved species according to the effective evaporation rate (Roelofs and Lelieveld, 1995). Rather we attempt a more mechanistic approach. As long as there is liquid water available (LWC greater than a threshold value), the liquid phase chemistry is calculated as described above. In case of higher liquid phase concentrations than allowed according to Henry's law for equilibrium, these species are released into the gas phase via the phase change mechanism described above. For ions, the lower water content raises their concentrations. This changes the dissociation equilibria and the rates of reaction pathways. In case of complete evaporation, i.e. if the LWC decreases below the threshold (droplet must then be considered as deliquescent aerosol), non-volatile species and ions produced by liquid phase chemical processes are transferred to aerosol species of the largest available mode. This also depends on the degree of coupling between the aerosol composition and the SCAV scheme. As a consequence new aerosol particles can be created. The volatile compounds are either directly released to the gas phase or through the chemistry scheme of the aerosol submodel, again dependent on the availability of a scheme that performs the process calculations.

\section{Application}

\subsection{Column model}

As described above a single column version of the submodel is available suitable for comparison with measurements at a specified location or for idealised case studies. As an example, the scavenging of nitric acid and formaldehyde calculated with this simplified column model is shown in Fig. 5. Each level of the column model has a vertical extent of $500 \mathrm{~m}$. A standard temperature profile is assumed. A cloud is placed at $1000 \mathrm{~m}$ above ground with a vertical extension of $1500 \mathrm{~m}$. The precipitation production leads to a rain rate of about $1 \mathrm{~mm} / \mathrm{h}$ within the cloud levels, resulting in a rain rate of about $1.5 \mathrm{~mm} / \mathrm{h}$ in the levels below the cloud base. Both species were initialised with a mixing ratio of $1 \mathrm{nmol} / \mathrm{mol}$. Fig. 5 depicts the temporal development of the vertical distribution of the mixing ratios. Because it changes by orders of magnitude, a logarithmic scale is applied. On the left side of the figure it can be seen that after only two hours almost all $\mathrm{HNO}_{3}$ is depleted from the gas phase in and below the cloud. This corresponds quite well with the scavenging coefficients given by Levine and Schwartz (1982). On the right side of Fig. 5 the scavenging of HCHO is shown. Because the simple mechanism selected for this application does not include any chemical HCHO reactions in the aqueous phase, only the transfer is calculated. Within the cloud layers significant uptake into the droplets takes place, evident from the decreasing gas phase mixing ratio. Below the cloud base, in an area with higher temperatures, some fraction of $\mathrm{HCHO}$ is released from the falling droplets, because of the temperature dependence of Henry's law coefficient. Therefore, an increase in the gas phase mixing ratio can be seen. Since the scheme is mass conserving the scavenging leads to a redistribution of $\mathrm{HCHO}$ between the cloud layers and those below the cloud, whereas the overall $\mathrm{HCHO}$ removal from the 

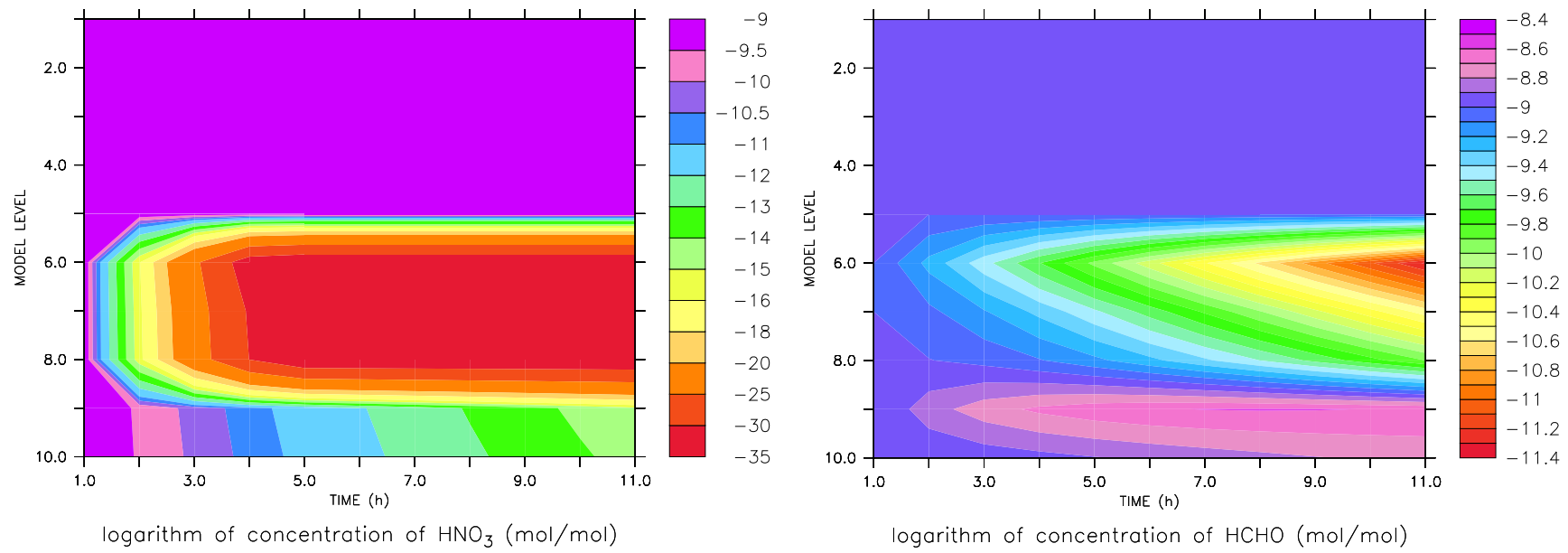

Fig. 5. Time series of gas phase $\log \left[\mathrm{HNO}_{3}\right]$ (left) and $\log [\mathrm{HCHO}$ (right), as influenced by scavenging in an atmospheric column with a precipitation rate of about $1.5 \mathrm{~mm} / \mathrm{h}$ over $10 \mathrm{~h}$. Each model level has a thickness of $500 \mathrm{~m}$.

column is determined by wet deposition, i.e. the precipitation flux in the lowest model layer.

\subsection{Global model}

The SCAV submodel has been applied on a global scale within the ECHAM5/MESSy (Roeckner et al., 2003; Jöckel et al., 2005) model system. Model simulations for periods of several years have been performed within an acceptable time frame. The coupling to the global scale is straightforward as the scheme is written according to the MESSy standard.

The choice of the chemical mechanism is quite important within a global modelling framework, because it determines the additional computing resources required, which can be substantial for a comprehensive set of reactions. A minimum mechanism as described above is quite suitable for long term climate studies while a detailed chemical reaction set can only be used for short-term process studies, e.g. for simulations of a period of up to one year. Detailed results will be presented in an upcoming paper (Tost et al., 2006 ${ }^{1}$ ).

Distinction between large scale and convective precipitation:

Since tracer tendencies are calculated for each grid-box, precipitation fluxes across upper and lower box boundaries have to be calculated. Large scale and convective precipitation need to be distinguished, as they are calculated separately in many models. Nevertheless, the same processes take place in all precipitation events regardless of the origin of the precipitation. A distinction of the wet deposition fluxes of each rain type is possible, e.g. to determine the effects separately.

\section{Convective scavenging:}

Since convective scavenging is closely related to convective tracer transport, these processes are addressed following a common principle. Two different approaches have been implemented. The first is a modification of the convective tracer flux within the convection scheme and the second an external convective tracer transport scheme (Lawrence and Rasch, 2005) (CVTRANS submodel, see http://www.messy-interface.org), which also includes an interface for the convective scavenging. This is essential because the two processes compete with respect to the transport of trace species. To take into account the scavenging by liquid water in the upper part of cumulus clouds, it is assumed that a fraction of the total convective water remains liquid below the freezing point. This fraction is assumed to decrease linearly with altitude.

\section{Technical realisation:}

The same routines for the physical and chemical process of the scavenging process are used for large scale and convective precipitation. The difference is that different input parameters and a separate coupling to the tracer transport for convective precipitation are used.

\section{Conclusions}

A new modular numerical scheme for scavenging of trace gases and aerosol particles has been developed. Because of its structure, the submodel is highly self-consistent and based on mechanistic process descriptions to the extent possible. It can be used both for large scale and convective clouds and precipitation. The scheme processes include scavenging as well as cloud and precipitation chemistry. 
Since the scheme is quite flexible it also allows application in a simplified form in a global general circulation model with acceptable computational effort, e.g. in long-term climate simulations.

\section{Outlook}

Since this submodel lacks the treatment of scavenging of gases by ice particles, this is a required further development which will be added in near future. Additionally, the scavenging of aerosol particles by frozen hydrometeors will be improved. The aerosol-cloud-interactions of the global model system ECHAM5/MESSy will be reformulated and from these results a new approach for the nucleation scavenging will be achieved.

This submodel has been applied in several multiyear simulations in the global chemistry climate model ECHAM5/MESSy and the data will be analysed and compared to wet deposition measurements in near future.

Acknowledgements. We are grateful to A. Sandu for providing the KPP software. We also thank M. Lawrence for the fruitful discussions and help with the convective tracer transport. Additionally we thank all the other MESSy developers and users for their support.

Edited by: M. Dameris

\section{References}

Andronache, C.: Estimated variability of below-cloud aerosol removal by rainfall for observed aerosol size distributions, Atmos. Chem. Phys., 3, 131-143, 2003.

Andronache, C.: Estimates of sulfate aerosol wet scavenging coefficient for locations in the Eastern United States, Atmos. Environ., 38, 795-804, 2004.

Beard, K. V. and Pruppacher, H. R.: A determination of the terminal velocity and drag of small water drops by means of a wind tunnel, J. Atmos. Sci., 26, 1066-1971, 1969.

Best, A. C.: The size distribution of raindrops, Q. J. R. Meteorol. Soc., 76, 16-36, 1950.

Crutzen, P. J. and Lawrence, M. G.: The Impact of Precipitation Scavenging on the Transport of Trace Gases: A 3-Dimensional Model Sensitivity Study, J. Atmos. Chem., 37, 81-112, 2000.

Damian, V., Sandu, A., Damian, M., Potra, F., and Carmichael, G. R.: The kinetic preprocessor KPP - a software environment for solving chemical kinetics, Comput. Chem. Eng., 26, 1567$1579,2002$.

Ervens, B., George, C., Williams, J. E., Boxton, G. V., Salmon, G. A., Bydder, M., Wilkinsons, F., Dentener, F., Mirabel, P., Wolke, R., and Herrmann, H.: CAPRAM 2.4 (MODAC mechanism): An extended and condensed tropospheric aqueous phase mechanism and its application, J. Geophys. Res., 108, 4426, doi: 10.1029/2002JD002202, 2003.

Feichter, J., Kjellström, E., Rohde, H., Dentener, F., Lelieveld, J., and Roelofs, G.-J.: Simulation of the tropospheric sulfur cycle in a global climate model, Atmos. Environ., 30, 1693-1707, 1996.
Frössling: The evaporating of falling drops, Beitr. Geophys., 52, 170-216, 1938.

Jöckel, P., Sander, R., Kerkweg, A., Tost, H., and Lelieveld, J.: Technical Note: The Modular Earth Submodel System (MESSy) - a new approach towards Earth System Modeling, Atmos. Chem. Phys., 5, 433-444, 2005.

Lawrence, M. G. and Crutzen, P. J.: The impact of cloud particle gravitational settling on soluble trace gas distributions, Tellus, 50B, 263-289, 1998.

Lawrence, M. G. and Rasch, P. J.: Tracer transport in deep convective updrafts: plume ensemble versus bulk formulations, J. Atmos. Sci., 62, 2880-2894, 2005.

Lelieveld, J. and Crutzen, P. J.: The Role of Clouds in Tropospheric Chemistry, J. Atmos. Chem., 12, 229-267, 1991.

Levine, S. Z. and Schwartz, S. E.: In-cloud and below-cloud scavenging of nitric acid vapor, Atmos. Environ., 16, 1725-1734, 1982.

Liang, J. and Jacob, D. J.: Effect of aqueous phase cloud chemistry on tropospheric ozone, J. Geophys. Res., 102, 5993-6001, 1997.

Martinsson, B. G., Frank, G., Cederfelt, S.-I., Swietlicki, E., Berg, O. H., Zhou, J., Bower, K. N., Bradbury, C., Birmili, W., Stratmann, F., Wendisch, M., Wiedensohler, A., and Yuskiewicz, B. A.: Droplet nucleation and growth in orographic clouds in relation to the aerosol population, Atmos. Res., 50, 289-315, 1999.

Mason, J. B.: The Physics of Clouds, Oxford University Press, 1971.

Pruppacher, H. R. and Klett, J. D.: Microphysics of Clouds and Precipitation, Kluwer Academic Publishers, 2000.

Roeckner, E., Bäuml, G., Bonaventura, L., Brokopf, R., Esch, M., Giorgetta, M., Hagemann, S., Kirchner, I., Kornblue, L., Manzini, E., Rhodin, A., Schleese, U., Schulzweida, U., and Tompkins, A.: The atmospheric general circulation model ECHAM5: Part 1, Tech. Rep. 349, Max-Planck-Institut für Meteorologie, 2003.

Roelofs, G.-J. and Lelieveld, J.: Distribution and budget of $\mathrm{O}_{3}$ in the troposphere calculated with a chemistry general circulation model, J. Geophys. Res., 100, 20 983-20 998, 1995.

Sander, R.: Modeling atmospheric chemistry: Interactions between gas-phase species and liquid cloud/aerosol particles, Surv. Geophys., 20, 1-31, 1999.

Sander, R., Kerkweg, A., Jöckel, P., and Lelieveld, J.: Technical Note: The new comprehensive atmospheric chemistry module MECCA, Atmos. Chem. Phys., 5, 445-450, 2005.

Sandu, A. and Sander, R.: Technical Note: Simulating chemical systems in Fortran90 and Matlab with the Kinetic PreProcessor KPP-2.1, Atmos. Chem. Phys., 6, 187-195, 2006.

Sandu, A., Verwer, J. G., Blom, J. G., Spee, E. J., Carmichael, G. R., and Potra, F. A.: Benchmarking stiff ODE solvers for atmospheric chemistry problems II: Rosenbrock solvers, Atmos. Environ., 31, 3459-3472, 1997.

Schwartz, S. E.: Mass-transport considerations pertinent to aqueous phase reactions of gases in liquid-water clouds, in: Chemistry of Multiphase Atmospheric Systems, NATO ASI Series, Vol. G6, edited by: Jaeschke, W., pp. 415-471, Springer Verlag, Berlin, 1986.

Seinfeld, J. and Pandis, S.: Atmospheric Chemistry and Physics, Wiley \& Sons, 1997.

Slinn, W. G. N.: Atmospheric Sciences and Power Production 1979, chap. 11, Precipitation Scavenging, U.S. Department of 
Energy, Washington, D.C., 1983.

Stier, P., Feichter, J., Kinne, S., Kloster, S., Vignati, E., Wilson, J., Ganzeveld, L., Tegen, I., Werner, M., Balkanski, Y., Schulz, M., and Boucher, O.: The Aerosol-Climate Model ECHAM5-HAM, Atmos. Chem. Phys., 5, 1125-1156, 2005.
Svenningsson, B., Hansson, H.-C., Martinsson, B., Wiedensohler, A., Swietlicki, E., Cederfelt, S.-I., Wendisch, M., Bower, K. N., Choularton, T. W., and Colvile, R. N.: Cloud droplet nucleation scavenging in relation to the size and hygroscopic behaviour of aerosol particles, Atmos. Environ., 31, 2463-2475, 1997. 